\title{
Small-Diameter Optical Fibre Sensor Embedment for Ambient Temperature Cure Monitoring and Residual Strain Evaluation of CFRP Composite Laminates Produced by Vacuum Assisted Resin Infusion
}

\author{
Helena Rocha ${ }^{1,2}$, Christopher Semprimoschnig ${ }^{3}$, João Pedro Nunes ${ }^{1}$ \\ ${ }^{1}$ Institute for Polymers and Composites, University of Minho, Guimarães, Portugal \\ ${ }^{2}$ PIEP - Innovation in Polymer Engineering, Guimarães, Portugal \\ ${ }^{3}$ European Space Agency, Noordwijk, The Netherlands \\ * Corresponding author (helenarocha@dep.uminho.pt)
}

\begin{abstract}
Out of autoclave (OoA) processing techniques, such as liquid composite moulding techniques (LCM) and, particularly, the vacuum assisted resin infusion (VARI) technique, are being used, with increasing success, in replacement of prepreg/autoclave technologies to produce structural aircraft/aerospace polymer composite parts, due to its better cost effectiveness and competitiveness. This work aims to embed Fibre Bragg grating (FBG) sensors to monitor the VARI manufacturing of carbon fibre reinforced polymer (CFRP) composites and evaluate the associated phenomena: ambient curing and post curing reactions and resulting residual strains. The curing kinetics of the epoxy resin system alone was initially studied through isothermal differential scanning calorimetry (DSC) tests and applying the isoconversional Friedman method, and further studied by strain monitoring during ambient curing and post curing resorting to FBG sensors. The FBG sensors in the CFRP laminates were able to detect a subtle increase of strain as infusion of the CFRP started and to measure decreasing strain as resin filled in the dry fabric layers. Subtle strain decrease revealed forming crosslink bonds. Compressive strains measured by the FBG sensors during post curing show that further crosslink takes place. A comparison of resultant residual strains was made between specimens with embedded FBG sensors on small-diameter optical fibres (SDOF) and on large-diameter optical fibres (LDOF).
\end{abstract}

Keywords: Carbon Fibre Reinforced Polymer Composite, Fibre Bragg grating sensor, Cure Monitoring, Ambient Temperature Curing, Vacuum Assisted Resin Infusion, Residual Strains

\section{Introduction}

Commercial aircraft industry has moved in the direction of polymer composite materials, replacing metallic materials, to produce lighter, less part-count and more complex structures, allowing to reduce fuel consumption and carbon dioxide emissions and ultimately decrease costs [1], [2]. Further cost savings may be achieved by composite manufacture through liquid composite moulding (LCM) techniques, replacing autoclave manufacturing [2]. Vacuum assisted resin infusion (VARI) is one of the LCM technologies [3] that has proved to be well-suited to produce advanced structural parts for aircraft and aerospace industries, as it allows the manufacturing of large components with good reproducibility, mechanical properties and having, simultaneously, high fibre and low void contents. It is also an eco-friendly and inexpensive technology. Monolithic panels of aircraft wings can be produced through VARI to fit the structural component, reducing the number of parts and fasteners, and consequently the complexity of the final structure [4].

Despite of the great mechanical properties and weight saving characteristics of composite materials, their failure is yet hard to foresee, since a combination of defects, such as fibre breakage and/or misalignment, matrix macro- or 
micro-cracking, material and stress discontinuities, fibre/matrix debonding and delaminations may be present simultaneously [5]. Fatigue and ageing might also lead to the failure of fibre reinforced polymer structures [1], [6].

Fibre Bragg grating (FBG) sensors, optical fibre-based sensors, are considered a matured technology regarding structural health monitoring (SHM) of composites [7]. FBG sensors have demonstrated to be capable of monitoring low impact damage, either under static or dynamic conditions [8]. They have the advantage over other types of fibre optic based sensors of being intrinsic sensing elements, as the acquired signal is encoded directly in the wavelength form, easing wavelength division multiplexing [9]. FBG sensors are multiplexed by inscribing gratings with periodically different refractive indexes and, therefore, distinct Bragg wavelengths. Typically, the length of FBG sensor varies between 2 and $20 \mathrm{~mm}$ [10]. Since FBG sensors are inscribed into the fibre without affecting its diameter, their application is possible on an extensive selection of applications requiring small diameter probes, such as strain mapping of advanced composite materials [9]. An FBG sensor comprises a narrowband reflector [11], obtained through a set of periodic gratings with a refractive index distinct of that of the core optical fibre material. The gratings are written into the fibre core, exposing the optical fibre (OF) to ultraviolet light [10], working as a mirror of a specific wavelength, the central Bragg wavelength [6]. FBG sensors follow the Bragg's law, where the Bragg wavelength, $\lambda_{B}$, is dependent on the effective refractive index of the gratings, $\eta_{\text {eff }}$, and on the grating period, $\Lambda$, as presented in equation 1. Once a local deformation is induced, a variation on the grating period is observed, producing a variation on the reflected central Bragg wavelength, which allows to detect the local strain [12]. A compressive strain produces a decrease of the Bragg wavelength value, while a tensile strain produces an increase of the Bragg wavelength value [8].

$$
\lambda_{B}=2 \eta_{e f f} \Lambda
$$

Temperature also produces a shift on the Bragg wavelength, which makes it mandatory to compensate for thermal strain, when only mechanical strain is of interest [13]. Thermal compensation can be achieved by using an extra strain free reference FBG sensor, where the Bragg wavelength shift can be attributed solely to thermal expansion/contraction, in the case that all FBG sensors are at the same temperature, or by encapsulating an extra reference FBG sensor into a capillary [12]. The fact that FBG sensors are sensitive to thermal strain, makes it easier for the FBG sensor to monitor curing reactions. Chehura et al. reported an initial strain increase as thermal expansion occurs when resin is heated, followed by a negative strain owing to polymerization shrinkage as curing initiates and, lastly, further negative strain is developed as further shrinkage may happen and the resin cools down [14]. Leng et al. evaluated extrinsic FabryPerot interferometer (EFPI) sensors and FBG sensors for cure monitoring of CFRP prepregs. A thermocouple was embedded for cure temperature monitoring. EFPI sensors revealed three curing stages, starting with an increase of compressive strain, followed by a somewhat even strain region, where most of the curing reaction occurred, finishing with a last growth of the compressive strain as matrix shrank upon cooling. The wavelength shift curve of the FBG sensor showed a similar shape to the temperature curve measured by the thermocouple during curing, showing that the temperature has a higher contribution to the Bragg wavelength shift than the mechanical shrinking strain. The curing stages were also identified in the curve of FBG wavelength shift [15]. Kang et al. embedded two FBG/EFPI hybrid sensors in perpendicular directions into unidirectional, symmetric cross-ply and fabric graphite/epoxy laminate prepregs, which were autoclave cured. High compressive strains were measured by the sensors in the transverse direction to the fibres, whereas low compressive strains were measured by the sensors in the same direction of the fibres. The authors attribute this behaviour to the large role of the matrix on the transverse properties of the composite material [16].

The embedding method and placement of optical fibre based sensors in the composite should be carefully considered to diminish the impairment of mechanical properties. In theory, the strength and modulus deterioration of the composite are dependent on the angle between the OF and adjacent reinforcing fibres orientation, laminate thickness, diameter of the $\mathrm{OF}$ and material of protective coating of the OF. Placing the OF parallel to the reinforcement fibres will generally result in a more uniform consolidation around the optical fibre, with minor defects and lower weakening 
of the composite mechanical properties [6]. The difference in diameter size between OF and carbon or glass fibre reinforcements, where the former is about 10 to 15 times larger than the latter, may produce some discontinuities [3]. Small-diameter optical fibres (SDOF) have shown to be a viable solution [17]-[20]. Takeda et al. have shown that large-diameter optical fibres (LDOF) present poor consolidation of the reinforcing carbon fibres and formation of matrix rich regions, compared to SDOF, when the optical fibres are placed parallel to reinforcing fibres [17].

This paper reports the embedding of FBG sensors in CFRP composite laminates produced by VARI process. To mitigate the impairment of optical fibre embedment on the mechanical properties of the composite laminates, this work used SDOF, which were placed parallel to the direction of the adjacent reinforcing fibres. FBG sensors were embedded at three different through thickness locations of the CFRP laminates: in between the two top layers, the two bottom layers and the two middle layers. The wavelength shift of the FBG sensors was acquired from the beginning of the production process, to follow infusion, ambient curing and post curing stages and evaluate residual strains resultant from the production process. The curing kinetics of the epoxy resin system alone was initially assessed resorting to isothermal DSC experiments to which the isoconversional Friedman method was applied. The wavelength shift of immerged FBG sensors was analysed during ambient curing and post curing of the resin system alone aiming to discern the contribution of the matrix component alone on the FBG wavelength shift during the curing stages of the CFRP composites.

\section{Materials and Experimental Techniques}

\subsection{Materials}

A bicomponent epoxy resin system, Biresin ${ }^{\circledR}$ CR83 resin with CH83-6 hardener from Sika, and unidirectional carbon fibre fabric UT350, supplied by Rebelco, with an areal weight of $340 \mathrm{~g} / \mathrm{m}^{2}$ and thickness of $0.67 \pm 0.10 \mathrm{~mm}$, were used to produce 10-layer symmetric CFRP laminates with the following layup sequence: [0/0/45/90/-45]s. This resin system and unidirectional carbon fibre fabric have been successfully used in other projects for aeronautic and some aerospace parts made by VARI process.

This work used single mode polyimide coated small diameter optical fibre, with $80 \mu \mathrm{m}$ outer diameter, from Technica. Each optical fibre had a strain and temperature sensitive $\mathrm{FBG}$ sensor, $\mathrm{FBG}_{\mathrm{S}+\mathrm{T}}$, and a temperature only sensitive FBG sensor, $\mathrm{FBG}_{\mathrm{T}-\mathrm{CAP}}$, with central wavelengths (CWL) at 1540 and $1550 \mathrm{~nm}$, respectively. The two sensors being $2.5 \mathrm{~cm}$ away from each other. Each $\mathrm{FBG}_{\mathrm{T}-\mathrm{CAP}}$ sensor was encapsulated inside a fused silica capillary tube, from Specanalítica Lda, as represented in Fig. 1. The capillary was cut to be about $4 \mathrm{~cm}$ long and had an internal and external diameter

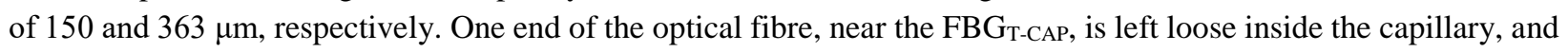
both extremities of the capillary were closed by epoxy resin, to prevent resin to go inside during the VARI process. One extremity of the capillary is glued to the optical fibre passing through (Fig. 1). As the FBG $_{\text {T-CAP }}$ is enclosed and can move freely inside the capillary, its CWL variation is only dependent on the coefficient of thermal expansion (CTE) of the optical fibre. On the other side, $\mathrm{FBG}_{\mathrm{S}+\mathrm{T}}$ sensors are in direct contact with the resin/laminate material, being the CWL variation dependent on the CTE of the optical fibre itself and on the mechanical strain of the surrounding material. Initial cure monitoring studies of the resin system alone and following vacuum assisted resin infusion production of CFRP laminates, used the above described FBG sensor construction. Additionally, type-K thermocouple was used for room temperature monitoring, using the NI 9211 temperature acquisition system from National Instruments. 


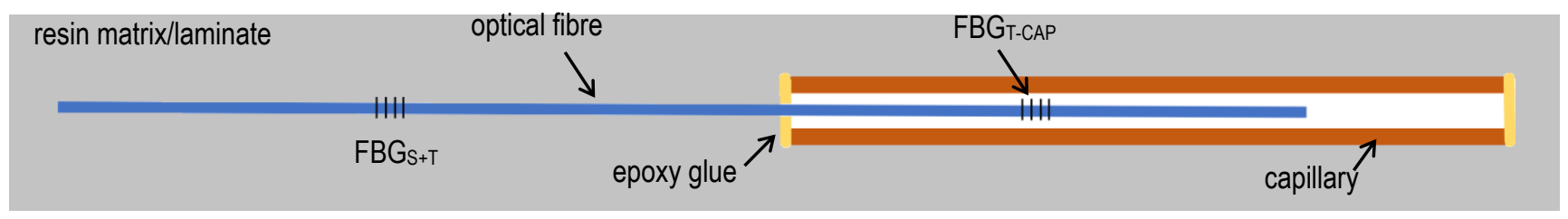

Fig. 1 Schematic representation of the optical fibre configuration depicting the isolation of the FBGT-CAP at the far end of the optical fibre into a capillary tube, where epoxy resin is used to close both ends, and the FBGS+T is in direct contact with the resin/laminate

For comparison purposes and to evaluate whether standard diameter optical fibres impose additional residual strains on CFRP laminates, monitoring of the CFRP production was conducted using large diameter optical fibres. These experiments used single mode $150 \mu \mathrm{m}$ outer diameter polyimide coated optical fibres from HBM FiberSensing S.A. with a $\mathrm{FBG}_{\mathrm{S}+\mathrm{T}}$ sensor and a $\mathrm{FBG}_{\mathrm{T}-\mathrm{CAP}}$ sensor with central wavelengths at 1540 and $1555 \mathrm{~nm}$, respectively. The $\mathrm{FBG}_{\mathrm{T}-\mathrm{CAP}}$ sensor is encapsulated into a $4 \mathrm{~cm}$ long microtube with a $900 \mu \mathrm{m}$ diameter.

By subtracting the change of central wavelength measured on the $\mathrm{FBG}_{\mathrm{T}-\mathrm{CAP}}$ sensor, $\Delta \lambda_{T}$, the portion of central wavelength change due to the effect of mechanical strain alone on the $\mathrm{FBG}_{\mathrm{S}+\mathrm{T}}$ sensor, $\Delta \lambda_{s}$, can be calculated. The imposed strain variation $\Delta \varepsilon(\mu \varepsilon)$, and temperature changes $\Delta T\left({ }^{\circ} \mathrm{C}\right)$, were calculated according to equations 2 and 3 , respectively, as given by the optical fibre manufacturers.

$$
\begin{aligned}
& \Delta \varepsilon=\Delta \lambda_{S} \times \mathrm{S}_{\varepsilon} \\
& \Delta \mathrm{T}=\Delta \lambda_{T} \times \mathrm{S}_{T}
\end{aligned}
$$

where $S_{\varepsilon}$ is the strain sensitivity and $S_{T}$ is the temperature sensitivity [21]. The used FBG sensors had strain and temperature sensitivities of $1.2 \mathrm{pm} / \mu \varepsilon$ and $10 \mathrm{pm} /{ }^{\circ} \mathrm{C}$, respectively.

\subsection{Experimental Techniques}

\subsubsection{Preparation of the CFRP Laminates}

CFRP laminates were produced following the VARI setup schematically shown in Fig. 2. The plates were produced with dimensions of $150 \times 100 \times 3.3(\mathrm{~mm})$ to be later exposed to low velocity impact events. The optical fibres were firstly overwrapped to protect their length going from the edge of the carbon fibre fabrics to the sealing tape that holds the vacuum. The optical fibres were overwrapped with flexible foam or thin film and adhesive tape, and peel ply was placed underneath and on top of the optical fibre wrapping to ease demoulding. A glass plaque was used as bottom mould where release agent HP7 from Marbocote was applied. Layers of carbon fibre fabric and OF were stacked with the desired orientation. Peel ply and flow enhancement medium were placed on top of the fabrics. Inlet and outlet resin flow lines were installed and connected to a resin container and a resin catch pot, respectively. Everything was sealed with plastic bag and sealing tape before applying vacuum. Resin and hardener were prepared according to the manufacturer instructions, in a weight proportion of $100 \%-30 \%$. The FBG data during curing was acquired by the IMON 256 USB High Speed interrogation monitor with a DL-BP1 1501A superluminescent LED from Ibsen Photonics, which has a maximum measurement frequency of $6000 \mathrm{~Hz}$ and operates in the wavelength range of 1525 $-1570 \mathrm{~nm}$, with a wavelength fit resolution of $0.5 \mathrm{pm}$, that translates to a strain resolution of about $0.4 \mu \varepsilon$ for the used FBG sensors. The signal acquisition was taken at $50 \mathrm{~Hz}$. The optical fibres have FC/APC optical connectors which are then plugged in to the light source.

The laminate was initially left to cure at room temperature under vacuum and, after demoulding, post cured at $70{ }^{\circ} \mathrm{C}$ for 8 hours, as indicated by the manufacturer. The post-cure was made inside an oven with initial heating and final 
cooling rates of about $15{ }^{\circ} \mathrm{C} / \mathrm{h}$ to reduce temperature gradients. Cooling down to $40{ }^{\circ} \mathrm{C}$ was imposed by the oven and the samples were then left to cool down to room temperature with the oven turned off. Two samples were prepared for each studied optical fibre location.

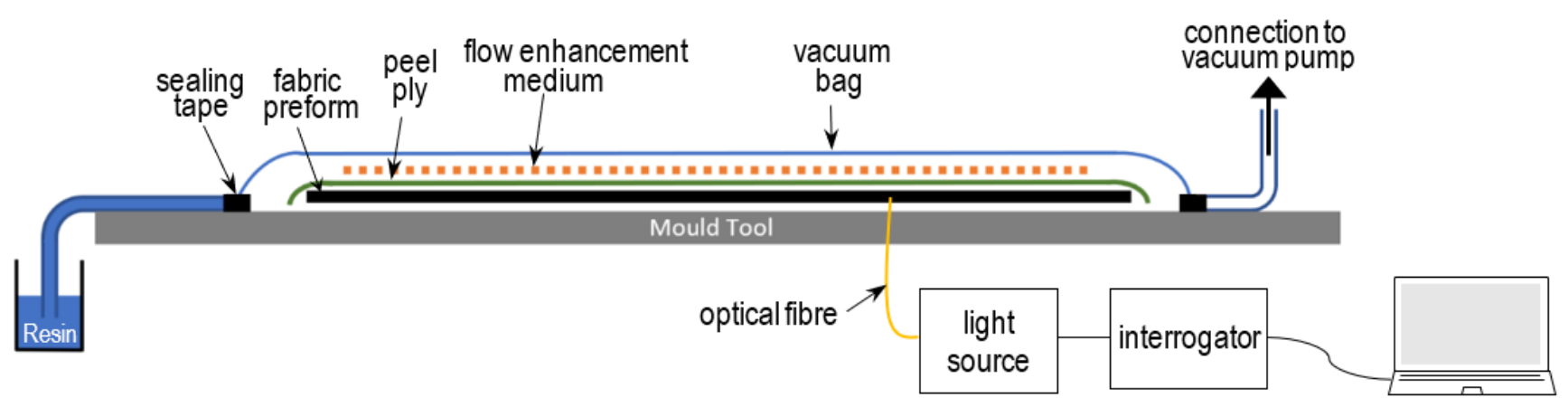

Fig. 2 Schematic representation of the VARI process and FBG monitoring set up

The locations of the optical fibres were chosen so that they are embedded in between two layers of reinforcing fabric with the same direction, resulting in minimal defects and least impairment of the composite mechanical properties. Position M-45 is the mid-plan and the OF is placed in between two carbon fibre layers oriented at $-45^{\circ}$. Position T0 and $\mathrm{B} 0$ are close to the top and bottom surfaces, respectively, and the OF are placed parallel to the reinforcing fibres, in between two layers oriented at $0^{\circ}$. These locations for OF embedment are illustrated in Fig. 3.

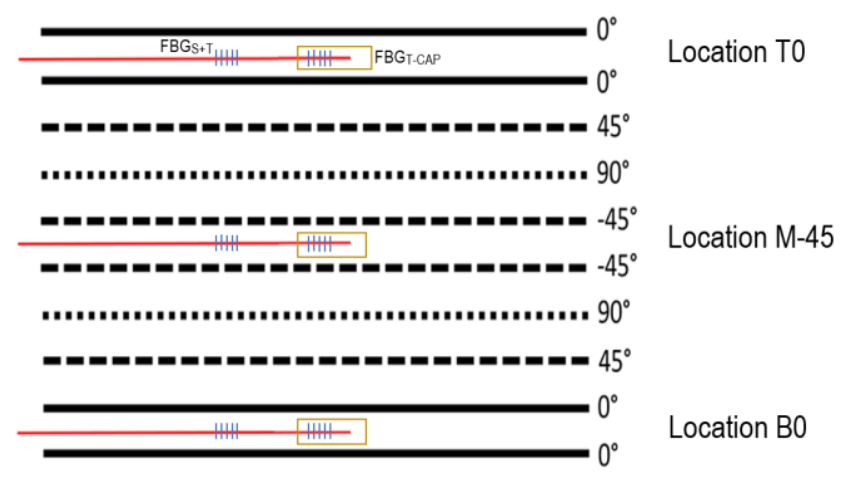

Fig. 3 Schematic representation of OF location through the thickness of the laminate

Fig. 4 shows a $150 \times 100 \times 3.3(\mathrm{~mm})$ specimen produced with an embedded SDOF. It is possible to see the protective materials used inside the vacuum bag and protective sleeves as supplied by the manufacturer.

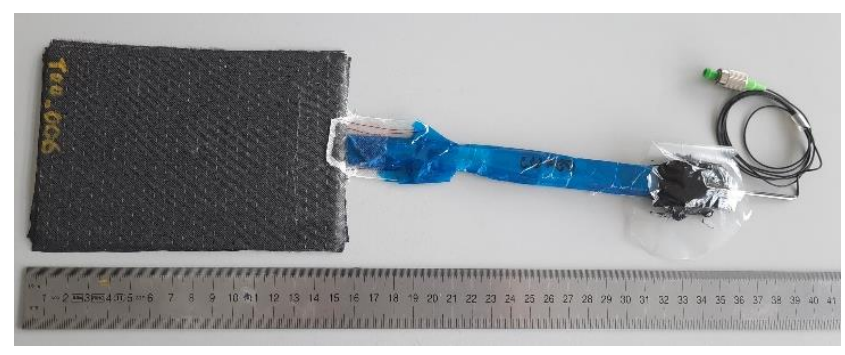

Fig. 4 Pictures of laminate specimen with embedded SDOF 


\subsubsection{Analysis of the Curing Reaction}

By using a DSC Q20 from TA Instruments, the exothermic curing reaction of the epoxy resin was studied resorting to multiple isothermal DSC experiments at distinct temperatures. The DSC records the heat flow as a dependent experimental variable of time $H(t)$, and the enthalpy, the total heat of reaction $H_{T}$, which is found by integrating the area of heat flow of the exothermic peak. The progression of the rate of heat flow is proportional to the reaction rate $d \alpha / d t$, as described by equation 4 .

$$
\frac{d \alpha}{d t}=\frac{1}{H_{T}} \frac{d H(t)}{d t}
$$

The reaction rate $d \alpha / d t\left(\mathrm{~s}^{-1}\right)$ of the curing reaction is generally dependent on temperature as described by the $k(T)$ function, the specific rate constant at temperature $T\left(\mathrm{~s}^{-1}\right)$, and on the degree of conversion, $\alpha$, given by the $f(\alpha)$ function, as stated by the following equation [22]:

$$
\frac{d \alpha}{d t}=k(T) \cdot f(\alpha)
$$

The temperature dependency on the reaction rate is often described by the Arrhenius law, i.e:

$$
k(T)=Z e^{-E_{a} / R T}
$$

where $Z$ is the pre-exponential factor $\left(\mathrm{s}^{-1}\right), E_{a}$ is the activation energy $\left(\mathrm{J} \cdot \mathrm{mol}^{-1}\right), T$ is the absolute temperature $(K)$, and $R$ is the gas constant, $8.314 \mathrm{~J} \cdot \mathrm{mol}^{-1} \cdot \mathrm{K}^{-1}$.

Initially, the simple $\mathrm{n}^{\text {th }}$ order and accelerating (or Sestak-Berggren) reaction model equations were applied to the experimental data, following procedure B of the ASTM standard E2070-13 [22], since the isothermal DSC curves (Fig. 5) presented the characteristic shape of a $\mathrm{n}^{\text {th }}$ order reaction. However, the Friedman model-free kinetics method [23], [24] presented a better fit with the experimental data and was used instead. This is an isoconversional method that assumes that the activation energy is independent of the temperature program, at any conversion $\alpha$. To determine the value of $E_{a}$, for a certain conversion $\alpha$, from each isothermal DSC experiment, equation 6 was rearranged into equation 5 and taken into its logarithmic form as:

$$
\ln [d \alpha / d t]=\ln Z f(\alpha)-\frac{E_{a}}{R} \cdot \frac{1}{T}
$$

Having equation 7 in the form of $y=b+m x$, it was solved through a linear regression analysis of the plot of $\ln (d \alpha / d t)$ against (1/T) (often called Friedman plot), in order to obtain $-E_{d} / R$ as its slope $(m)$ and $\ln Z \mathrm{f}(\alpha)$ the y-intercept at the origin (b). Once $E_{a}$ and $\mathrm{Zf}(\alpha)$ were found, equation 8 was integrated, resulting equation 9 , to find the time, $t_{\alpha}$, to reach a conversion $\alpha$, at an isothermal temperature, $T_{2}$, for which there is no measurement available [25].

$$
\begin{gathered}
\frac{d \alpha}{d t}=Z e^{-E_{a} / R T} \cdot f(\alpha) \\
t_{\alpha}=\int_{0}^{t_{\alpha}} d t=\int_{0}^{\alpha} \frac{d \alpha}{[Z \cdot f(\alpha)] \cdot e^{-E_{a} / R T_{2}}}=\frac{1}{[Z \cdot f(\alpha)] \cdot e^{-E_{a} / R T_{2}}} \int_{0}^{\alpha} d \alpha=\frac{\alpha}{[Z \cdot f(\alpha)] \cdot e^{-E_{a} / R T_{2}}}
\end{gathered}
$$

Initially, a dynamic DSC test was performed at a constant heating rate of $10{ }^{\circ} \mathrm{C} / \mathrm{min}$, between -30 and $+250{ }^{\circ} \mathrm{C}$, to define the temperatures to be used in the subsequent isothermal DSC tests, and measure the total enthalpy of curing. The isothermal DSC experiments were taken at $70,80,90$ and $100^{\circ} \mathrm{C}$ for progressively longer periods of time, between 
3 and 6 hours, to obtain a flat line of heat flow by the end of each experiment, ensuring full conversion of the curing reaction.

A big batch of about $50 \mathrm{~g}$ of resin and hardener were mixed in a $100 \%-30 \%$ weight ratio, to ensure a good representation of the resin system. Each sample having $26-32 \mathrm{mg}$ was placed in an aluminum crucible with a small hole in the lid and stored in a refrigerator at $-15{ }^{\circ} \mathrm{C}$ to prevent curing before the DSC tests. The DSC was initially pre-heated to the isothermal temperature and only then the sample was removed from the refrigerator and quickly placed in the DSC cell. Data recording was initiated about 1 minute later as soon as the isothermal temperature was equilibrated. The Kinetics Neo software from Netzsch was used to apply the Friedman method to the experimental DSC data to obtain $E_{a}$ and make isothermal predictions of the resin curing at ambient conditions, for temperatures ranging from 17 to $25^{\circ} \mathrm{C}$.

The curing of the epoxy system alone was monitored resorting to a SDOF having a $\mathrm{FBG}_{\mathrm{S}+\mathrm{T}}$ and a $\mathrm{FBG}_{\mathrm{T}-\mathrm{CAP}}$ sensor. About $50 \mathrm{~g}$ of resin was poured into a plastic plate to achieve a thickness of approximately $4 \mathrm{~mm}$, to resemble the resin curing behaviour that would be approximately expected in the CFRP laminate. The optical fibre was immersed in the middle area of the plate to acquire the CWL of the FBG. The thermocouples measured the laboratory temperature during ambient curing and the oven temperature during post curing. The curing degree of the resin was assessed 40 hours after ambient curing and after post curing procedure, by measuring the residual enthalpy of curing at each of these stages and comparing them to the total enthalpy of curing. The residual enthalpy of curing was measured by the area of the exothermic peak in the first heat of heat-cool-heat DSC cycles. Samples of about $7 \mathrm{mg}$ were heated from 30 to $200{ }^{\circ} \mathrm{C}$ in a first cycle, cooled down to $25^{\circ} \mathrm{C}$, and again heated up to $200{ }^{\circ} \mathrm{C}$ in a second cycle. Both heating stages and cooling used a temperature ramp of $10{ }^{\circ} \mathrm{C} / \mathrm{min}$ and a $5 \mathrm{~min}$ isothermal period was held at every end. All DSC tests were performed under nitrogen gas with a $50 \mathrm{ml} . \mathrm{min}^{-1}$ flow.

\section{Cure monitoring}

\subsection{Resin Curing}

\subsubsection{Curing kinetics}

The curing kinetics of the epoxy resin system alone was firstly evaluated by isothermal DSC studies, following the model-free isoconversional Friedman method [23], [24]. The isothermal DSC experiments showed the peak of exothermic curing right at the beginning of each isothermal test (see Fig. 5), which is the typical curve shape of a ${ }^{\text {th }}$ order reaction. Therefore the experimental data was initially modelled by the $\mathrm{n}^{\text {th }}$ order reaction model equation and then by the Sestak-Berggren model equation [22]. Nonetheless, the Friedman model-free kinetics method, described in the previous section was used instead as it showed a better fitting than the model-based approaches. Experimental and model differences arise attending that curing is taking place at a high rate in the beginning of each isothermal DSC test and it is not possible to measure the heat flow before the temperature has stabilized at the set isothermal temperature.

The Friedman plot (Fig. 6 (a)) was then constructed to allow calculating $E_{a}$ by using the linear regression of each conversion line as it is presented in Fig. 6 (b). As may be seen, the curing reaction has a higher heat flow and thus higher conversion rate at the beginning of the isothermal, which results in a higher $E_{a}$ at that point. The maximum activation energy was calculated to be about $73.5 \mathrm{~kJ} / \mathrm{mol}$ at $\alpha=0.01$, decreasing to about $13.4 \mathrm{~kJ} / \mathrm{mol}$ at $\alpha=0.99$. As the curing reaction progresses, being generally a diffusion-controlled process, the mobility of the molecules decreases after the gel point, resulting in lower reaction rates and lower $E_{a}[26]$. 


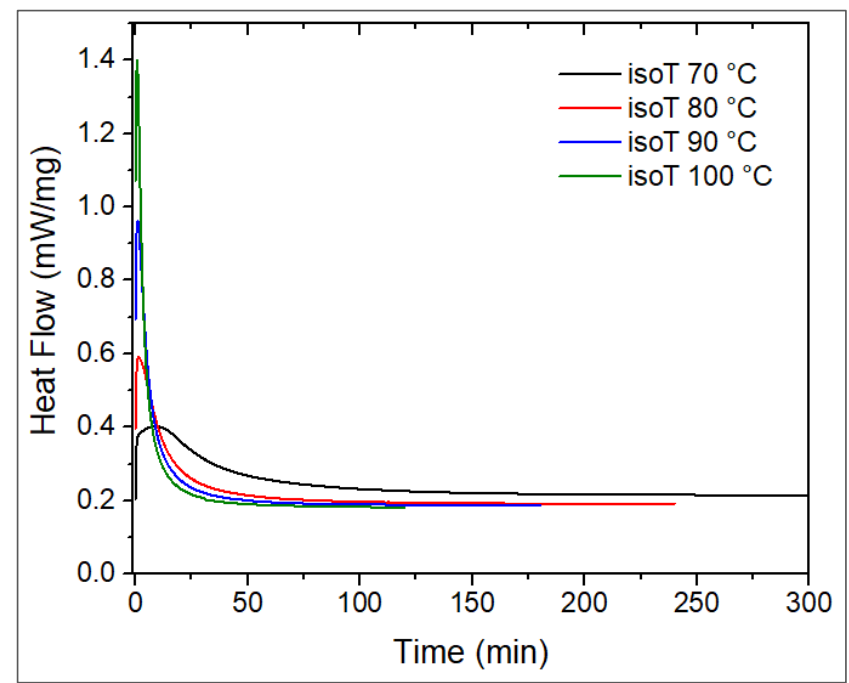

Fig. 5 Measured heat flow during isothermal DSC experiments at 70, 80, 90 and $100{ }^{\circ} \mathrm{C}$
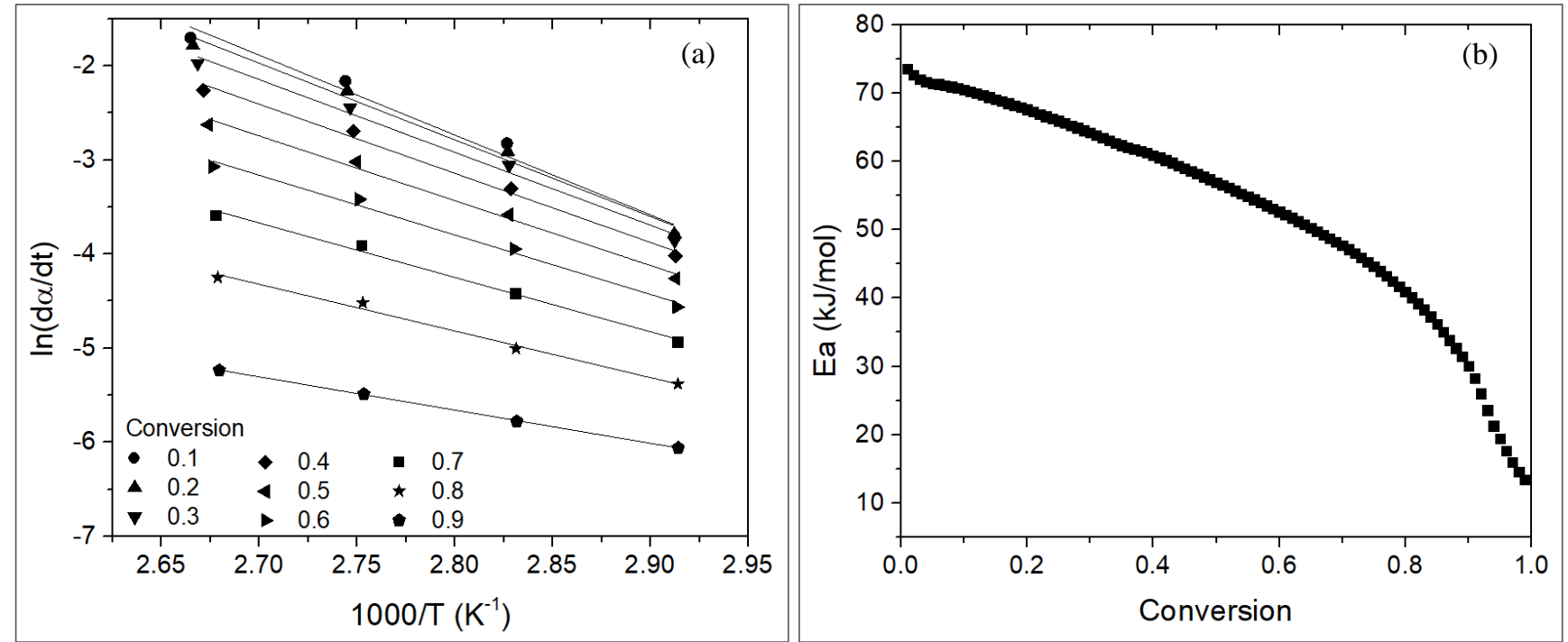

Fig. 6 (a) Friedman plot for calculation of activation energy at different conversions presented in (b)

As Fig. 7 shows, a good agreement was found $\left(\mathrm{R}^{2}=0.995\right)$ between experimental data and the theoretical fit plotted using the values determined for $E_{a}$ and y-intercepts, which gave confidence to make isothermal predictions for the curing of the epoxy system for lower temperatures. 


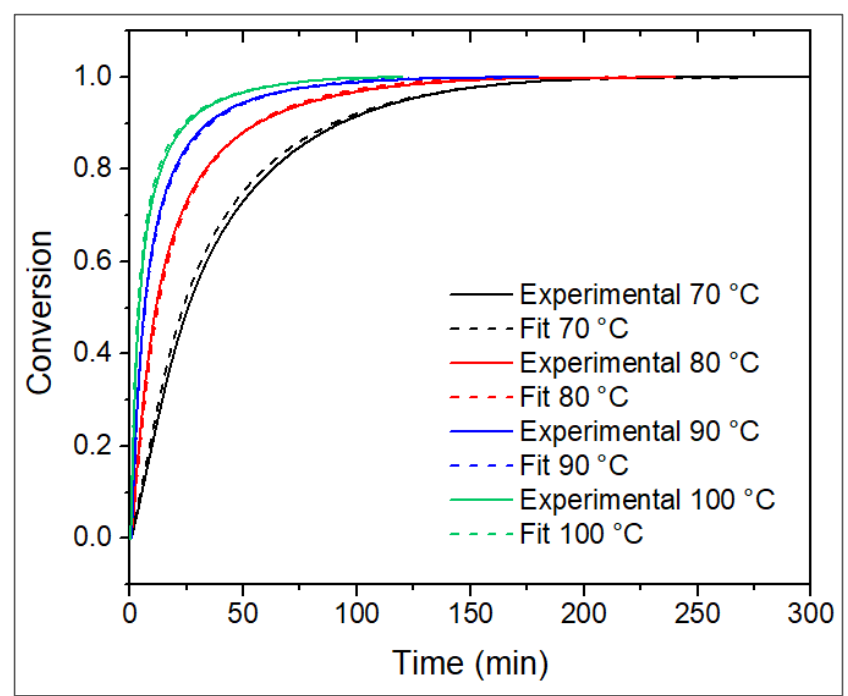

Fig. 7 Comparison of experimental curing conversion data and Friedman method fitting

Isothermal curing predictions for temperatures between $17-25^{\circ} \mathrm{C}$, are shown in Fig. 8 . The predictions show that, a small temperature difference of $8^{\circ} \mathrm{C}$ can result in a time difference of about 22.4 hours to reach full curing, varying from 52.8 hours at $17^{\circ} \mathrm{C}$ to 30.4 hours at $25^{\circ} \mathrm{C}$.

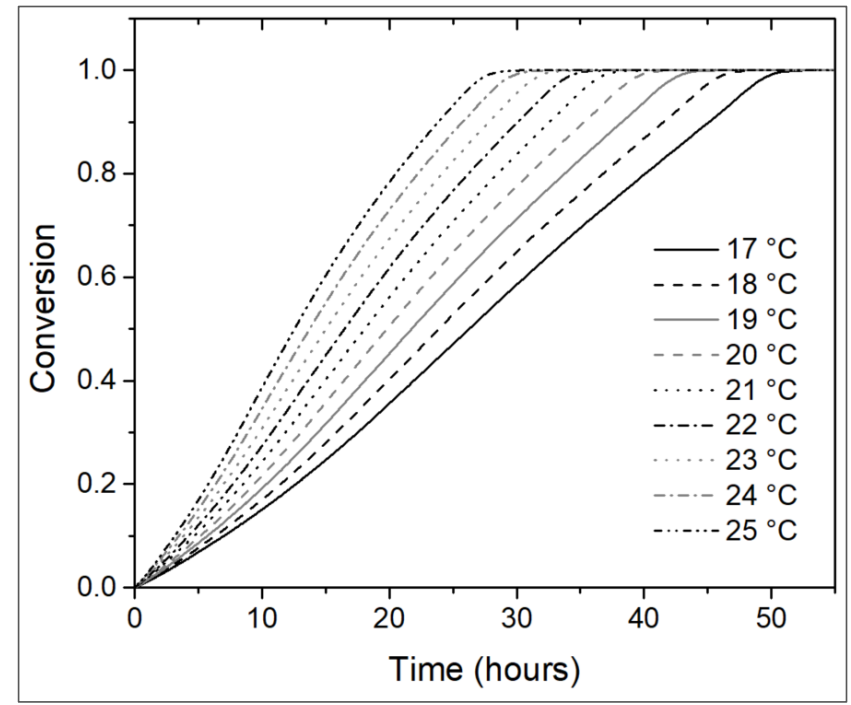

Fig. 8 Isothermal curing predictions for temperatures between 17 and $25{ }^{\circ} \mathrm{C}$

\subsubsection{Epoxy Cure Monitoring}

The curing of the epoxy system alone was monitored resorting to a bare and an encapsulated FBG sensor. These experiments aimed to validate the use of the FBG sensors for cure monitoring. Fig. 9 shows the strain and temperature change calculated from the FBG wavelength shift data during the cure monitoring of the resin system and the laboratory temperature measured by a type-K thermocouple. Following an initial strain decrease as the FBG sensors stabilize in the casted epoxy resin, the strain starts to increase, due to the developing network of covalent bonds, reaching a maximum of approximately $92 \mu \varepsilon$ after 18.3 hours. A decrease of temperature is measured by the encapsulated $\mathrm{FBG}_{\mathrm{T}-\mathrm{CAP}}$ sensor, which is explained by the initial temperature difference between the optical fibre and 
resin. Afterwards, the resin shrinkage due to crosslinking leaves the FBG under compressive strain, allowing to calculate a strain to decrease by about $322 \mu \varepsilon$, when it reaches a strain value close to $-230 \mu \varepsilon$ at 40 hours of ambient curing. The $\mathrm{FBG}_{\mathrm{T}-\mathrm{CAP}}$ sensor revealed to be highly sensitive to the laboratory temperature variations, as it can be observed by the temperature increase measured by both $\mathrm{FBG}_{\mathrm{T}-\mathrm{CAP}}$ sensor and thermocouple variation measured between $16-20$ hours.

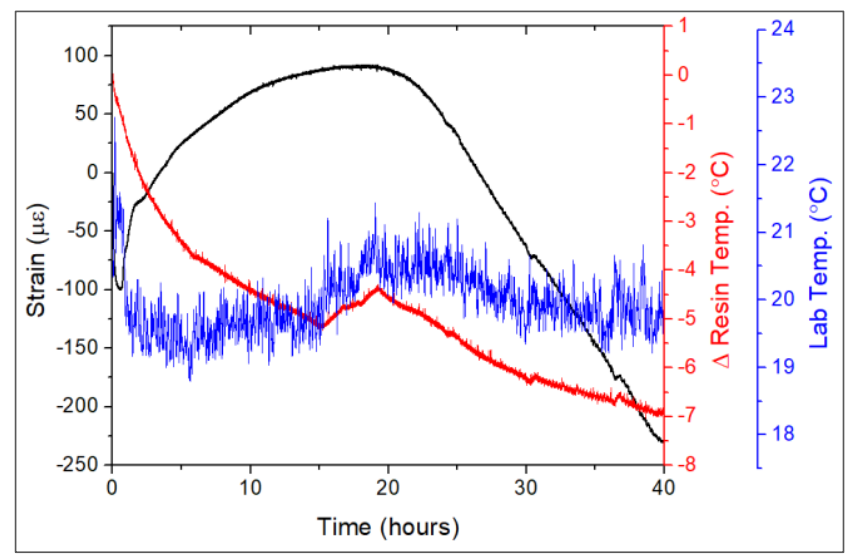

Fig. 9 Ambient cure monitoring of the epoxy resin system through FBG sensors and type-K thermocouple

At the time data recording was stopped, the resin has hardened but was not fully cured, since strain was still showing a downward progression. Looking at the isothermal curing predictions in Fig. 8 for temperatures between 19 and 20 ${ }^{\circ} \mathrm{C}$, it would be expected that full curing occurs only after $41-44$ hours. According to these same predictions, 40 hours of ambient curing at $19{ }^{\circ} \mathrm{C}$ would result in a conversion of 0.93 , while at $20^{\circ} \mathrm{C}$ would result in a conversion of 0.99. Yet, a DSC test performed on a small sample of the ambient cured resin allowed to calculate a residual enthalpy of curing of about $108.2 \mathrm{~J} / \mathrm{g}$, which corresponds to a cuing conversion of 0.71 . Such conversion difference can be due to distinct localized curing degrees in the resin sample and to the small sample size used in the DSC test. Further curing was observed in post curing process, as it can be seen in Fig. 10. The epoxy resin was subjected to the post curing process, as suggested by the supplier, $70{ }^{\circ} \mathrm{C}$ for 8 hours, with heating and cooling rate of about $15^{\circ} \mathrm{C} / \mathrm{h}$.
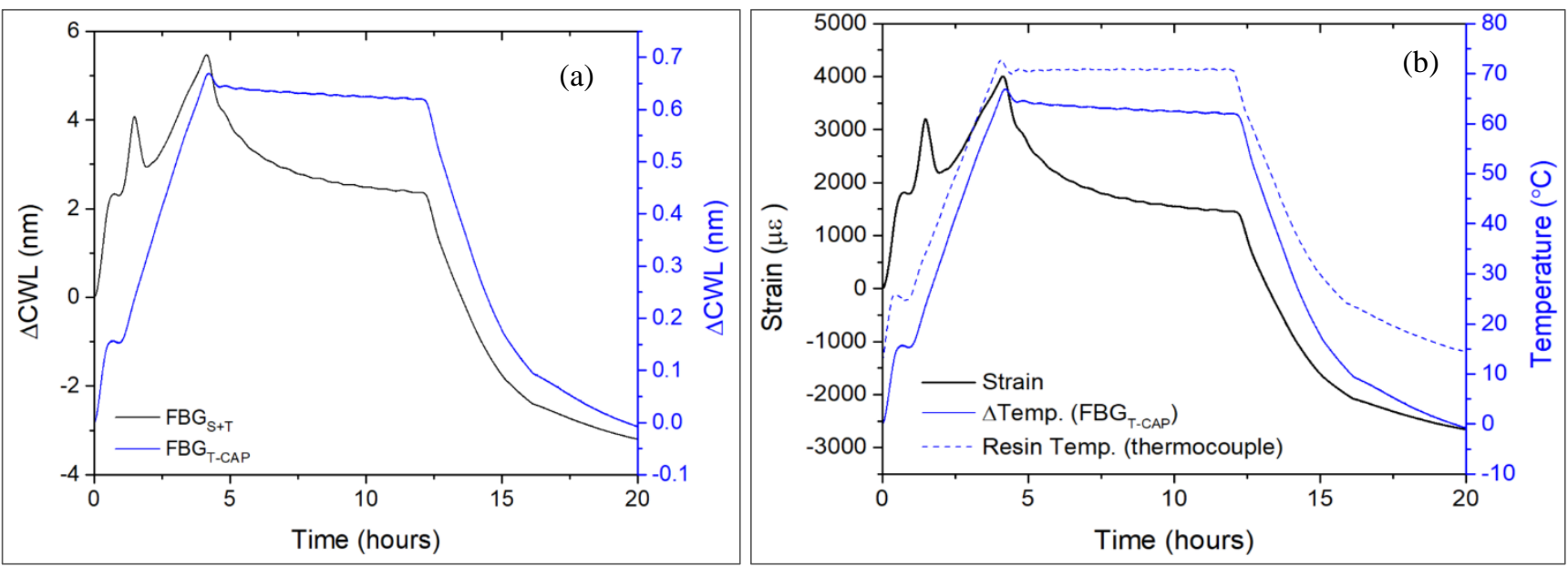

Fig. 10 Post cure monitoring of the epoxy resin showing (a) the CWL shift measured by the FBG sensors and (b) respective calculated strain and temperature shift, and resin temperature measured by a type-K thermocouple 
During the initial part of the heating stage, the strain measured by the FBG sensor changes as temperature changes, due to the resin thermal expansion/ contraction. During the heating stage, when the thermocouple was reading a temperature of approximately $35^{\circ} \mathrm{C}$ at about $1.56 \mathrm{~h}$, the strain decreased for about 25 minutes, while the resin kept warming up following the imposed heating rate. This demonstrates that shrinkage due to crosslinking is taking place. While at around 2 hours of post curing the stain starts to increase again, it is noticeable that the slope of strain curve is not as high as the slope of the temperature curve, showing that cure shrinking, and resin thermal expansion are competing at this moment. The strain reaches a maximum of $4004 \mu \varepsilon$ at the beginning of the isothermal period. During the isothermal period, the strain decreases slowly, showing that crosslink bonds are still forming, while thermal expansion stops as the temperature is kept constant. As the strain was still slightly decreasing, it indicates that the resin plate did not cure completely by the end of the isothermal period. As temperature is decreased in the cooling stage, thermal contraction acts on the $\mathrm{FBG}_{\mathrm{S}+\mathrm{T}}$ sensor and compressive strain is imposed on it. A compressive strain of about $-2762 \mu \varepsilon$ was calculated at the end of the post curing process. The shape of CWL shift curve of the $\mathrm{FBG}_{\mathrm{S}+\mathrm{T}}$ sensor (Fig. 10 (a)) closely matches the shape of the strain curve (Fig. 10 (b)), showing that the effect of mechanical strain is stronger than the effect of temperature for such a sample made of neat resin, as opposed to what is observed for the CFRP laminates in Fig. 13. The ambient curing produced much lower compressive strains than the post curing procedure, showing that higher temperatures lead to higher residual strain.

A DSC test was performed to a small sample of the post cured resin to evaluate the cuing conversion degree. A residual enthalpy of curing of about $4.6 \mathrm{~J} / \mathrm{g}$ was measured in the first heating step, revealing a conversion degree of 0.99 , reaching almost full conversion.

\subsection{CFRP Laminate Cure Monitoring}

A slight strain increase, in the order of 20 to $50 \mu \varepsilon$, was observed as resin started flowing into the dry fibres. This pressure increase puts the $\mathrm{FBG}_{\mathrm{S}+\mathrm{T}}$ sensor under tensile strain. Fig. 11 shows an example of strain monitoring on a specimen having the optical fibre at M-45 location up to 12 minutes past beginning of signal acquisition. The small peak is followed by a steep decrease of strain as the resin fills in the voids in between the dry carbon fibre reinforcement, compressing the $\mathrm{FBG}_{\mathrm{S}+\mathrm{T}}$ sensor, and an inflection point is visible. Following the steep decrease, strain stays relatively constant for the remaining time of ambient curing. This behaviour was observed among all the specimens, except for the sample shown in Fig. 12 (a).

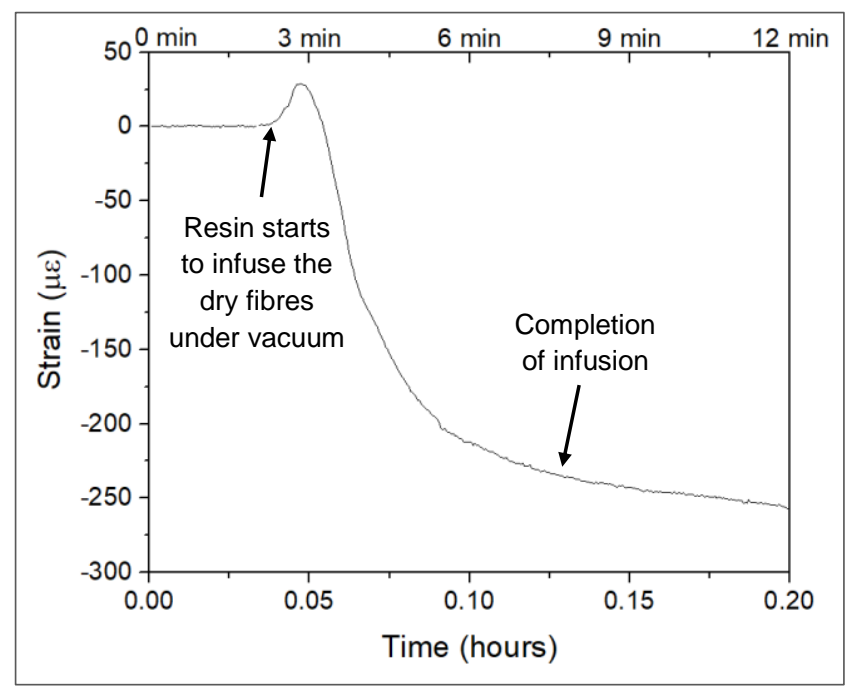

Fig. 11 Strain measured during initial 12 min of cure monitoring on a specimen with OF at M-45 location 
All the temperature sensitive FBG sensors revealed to be very sensitive to room temperature variations induced by the daily laboratory activities. The thermocouple measuring the laboratory temperature allowed to conclude that the temperature changes measured by the $\mathrm{FBG}_{\mathrm{T}-\mathrm{CAP}}$ sensos are due to temperature fluctuations in the laboratory and are not produced in the resin by the curing reaction. Examples of strain and temperature change curves, measured by the FBG $_{\text {T-CAP }}$ sensors, during the full room temperature curing process for specimens with small diameter optical fibre at (a) T0, (b) B0 and (c) M-45 locations, as well as the laboratory temperature, are presented in Fig. 12. While, generally, most of the samples showed a strain plateau (indicated by a two-sided arrow in Fig. 12 (b) and (c)) after the sudden strain decrease after resin fill up, the sample shown in Fig. 12 (a), with the FBG sensor at T0 location, showed a strain increase starting at about 3 hours. Although the wavelength variation data of the temperature sensitive FBG sensors was used to compensate for the temperature effect on the $\mathrm{FBG}_{\mathrm{S}+\mathrm{T}}$ sensors, some degree of temperature influence on the strain curves is still noticeable (indicated with arrow signs), which may explain some fluctuations observed in the strain curves. The FBG sensors take very localized measurements and the CWL shift produced on the $\mathrm{FBG}_{\mathrm{T}-\mathrm{CAP}}$ sensor may not entirely match the CWL shift produced by temperature on the $\mathrm{FBG}_{\mathrm{S}+\mathrm{T}}$ sensor. On the other side, as the temperature increases or decreases, the laminate may expand or shrink, producing a tensile or compressive strain, respectively, on the $\mathrm{FBG}_{\mathrm{S}+\mathrm{T}}$ sensor. Yet, about 27.2 hours after infusion, strain starts to decrease in the FBG sensor at T0 location. Similarly, the FBG sensor at B0 location (Fig. 12 (b)) starts to present a strain decrease at 28.6 hours. The FBG sensor at M-45 location (Fig. 12 (c)) presents a strain decrease much earlier, at around 12.6 hours. These are a wide range of values that differ from -5.7 hours to +10.3 hours compared to the 18.3 hours after which compressive strains were applied on the resin system alone. It is noticeable the difference between the strain curve of the CFRP laminates cured under vacuum and of the resin system cured under ambient pressure. Considering the cure of CFRP laminates under vacuum, after infusion, the produced compressive strains are only in the range of 20 to 30 $\mu \varepsilon$, in contrast to the cure monitoring of the resin system alone at ambient conditions, where a compressive strain of about $322 \mu \varepsilon$ was measured. It can be attributed to the high level of compactness imposed on the carbon fibre fabric by the vacuum pressure and to the small amount of resin when compared to the neat resin system. A correlation between optical fibre positioning along the laminate thickness and FBG ability to monitor curing was not found. 

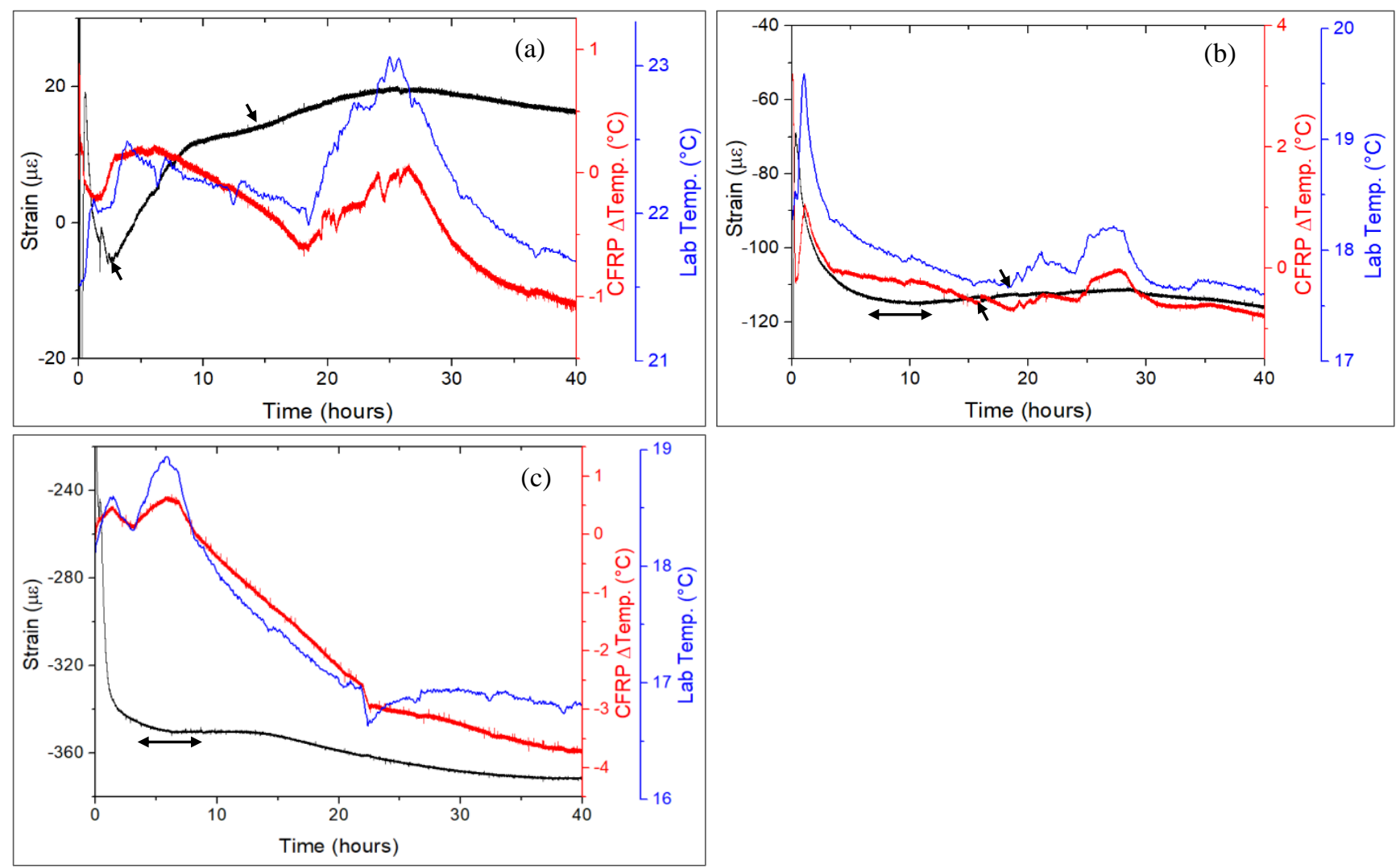

Fig. 12 room temperature cure monitoring of specimens with SDOF at (a) T0, (b) B0 and (c) M-45 location. Note that the strain scales have been zoomed in to better show the strain variation; the strain at time zero starts with strain values around zero, as the wavelength value at time zero of infusion was considered to be the reference Bragg wavelength

The central wavelength of the FBG sensors (Fig. 13 (a)) was also recorded during post curing process, for one sample of each location studied. The developed strain and temperature change, along with the imposed temperature profile recorded by the oven, are plotted in Fig. 13 (b) for a specimen with the OF embedded at location B0. As the temperature increases, the strain increases due to thermal expansion of the resin until it reaches a maximum point where strain starts to decrease. Just like observed in the post curing of the resin system alone, here there are further crosslink bonds forming as well, causing the resin to shrink and strain to decrease. Strain decreases during the initial 2 hours of the isothermal period and it is approximately constant for the remainder time of the isothermal step, showing that most of the curing happened up to the initial 2 hours of the isothermal period. The strain decreases upon cooling as resin shrinks and applies a compressive stress on the $\mathrm{FBG}_{\mathrm{S}+\mathrm{T}}$ sensor. The slope of strain vs. time curve changes according to the cooling rate. The shape and value of the wavelength variation curve of the $\mathrm{FBG}_{\mathrm{S}_{+} \mathrm{T}}$ sensor is very similar to the wavelength variation curve of the $\mathrm{FBG}_{\mathrm{T}-\mathrm{CAP}}$ sensor for most of the curing process, which shows that a large portion of the wavelength variation in the $\mathrm{FBG}_{\mathrm{S}+\mathrm{T}}$ sensors is promoted by temperature variations rather than mechanical strain, oppositely to what happens in the post cure monitoring of the resin system where the $\mathrm{FBG}_{\mathrm{S}+\mathrm{T}}$ sensor suffers a much higher CWL shift owing to mechanical strain. The deviation from the linear strain increase during the heating stage was observed at around $1.11 \mathrm{~h}$ for a period of about 6 minutes, when the temperatures in the laminate raised by about $2{ }^{\circ} \mathrm{C}$, as measured by the $\mathrm{FBG}_{\mathrm{T}-\mathrm{CAP}}$ sensor. In turn, at that time interval, the oven registered a temperature raise from $42.2{ }^{\circ} \mathrm{C}$ up to $43.6^{\circ} \mathrm{C}$. This strain curve perturbation is showing up at higher temperatures than in the epoxy plate, which happened at around $35^{\circ} \mathrm{C}$. At the end of cooling the compressive strain stabilized at a value of about $-100 \mu \varepsilon$, a much lower value than what was measured at the end of post curing of the resin, $-2762 \mu \varepsilon$. This can be explained by the small amount of resin in the CFRP and by the near zero CTE of the carbon fibres. 

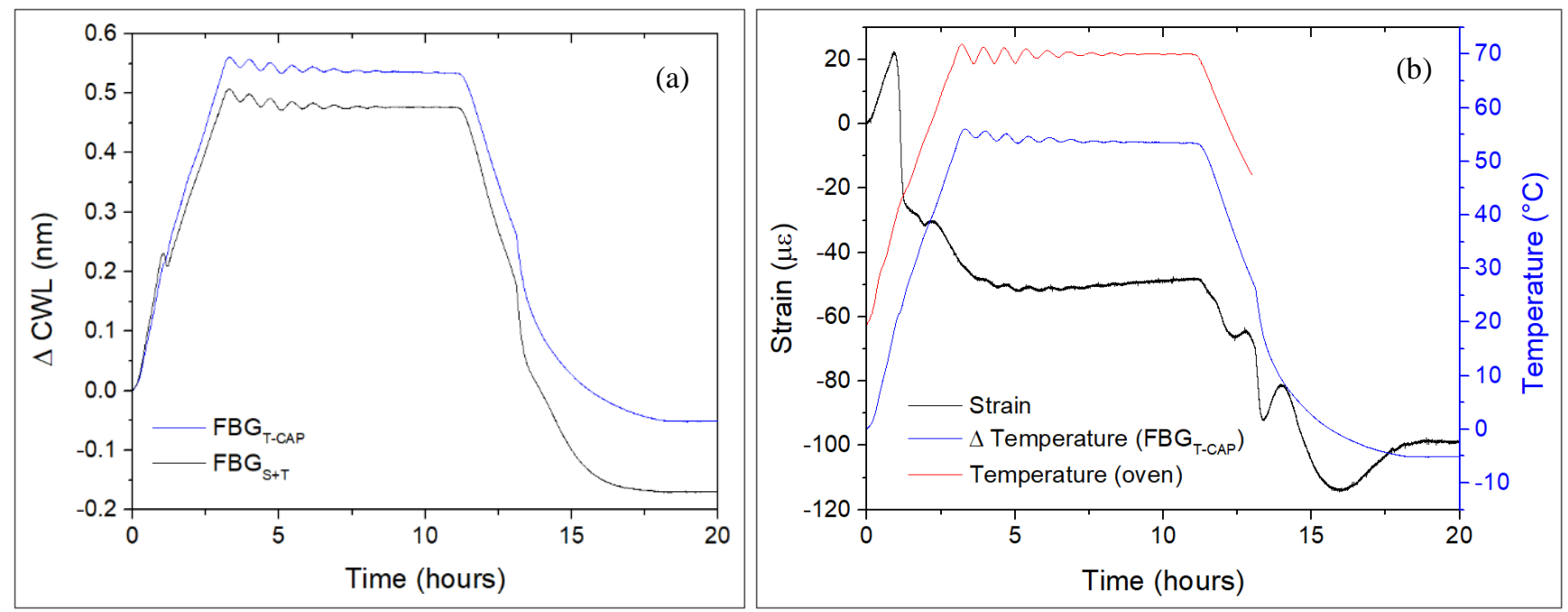

Fig. 13 Post cure monitoring of specimen with SDOF at location B0: (a) CWL change measured on FBGT-CAP and FBGs+T and, (b) correspondent calculated strain and temperature variation, and imposed temperature profile recorded by the oven

FBG sensors may not be able to evaluate the curing conversion at ambient curing but they are, certainly, a useful approach for high temperature curing resins and post curing monitoring, when the subtle temperature fluctuations measured during ambient curing, highly contributing to the shape of FBG wavelength shift, are negligible.

\section{Residual Strains}

The use of the FBG sensors allowed to evaluate the residual strains developed at different stages of the VARI process. It was observed that the preparation of the VARI set up, fixing and placing of the optical fibre in between CF plies during preform and vacuum bag preparation already induced either compressive or tensile strain on the FBG sensors. An example of the wavelength spectrum shift is presented in Fig. 14 for the SDOF placed at location B0. The Bragg wavelength of the $\mathrm{FBG}_{\mathrm{S}+\mathrm{T}}$ increased when embedded and under vacuum in the dry preform, right before infusion, when compared to the free condition ("as received" spectrum), revealing that the sensor is under tension. This condition was not observable for all the samples, some of them were under tension, others under compression, which is expected in such a manual embedding procedure. Nevertheless, as expected, most of the samples present a tensile pre-strain since they were tightly fixed to the sealing tape to be well aligned with the dry carbon fibre reinforcement. The pre-strain imposed in the VARI set up was calculated by the variation in the Bragg wavelength between the spectra of the optical fibre taken "as received" and just before infusion and resorting to equations 2 and 3. Examples of the pre-strain values observed in each optical fibre location are summarized in table 1. It should be noted that these FBG spectra data are very localized measurements in both time and area of the sample and may not entirely represent the real residual strain. Furthermore, the spectrum wavelength resolution is very low, $0.16 \mathrm{~nm}$, corresponding to a strain of about $133 \mu \varepsilon$, which may fail to accurately measure the Bragg wavelength peak. For instance, the "As received" spectrum clearly did not present a symmetric peak. To minimize erroneous strain calculation, the spectra data was fit to an areal based Gaussian function, using the fityk software, to find a more realistic CWL peak. Nonetheless, these pre-strains imposed by the preform preparation do not influence the final properties of the laminate and following strain measurements. 


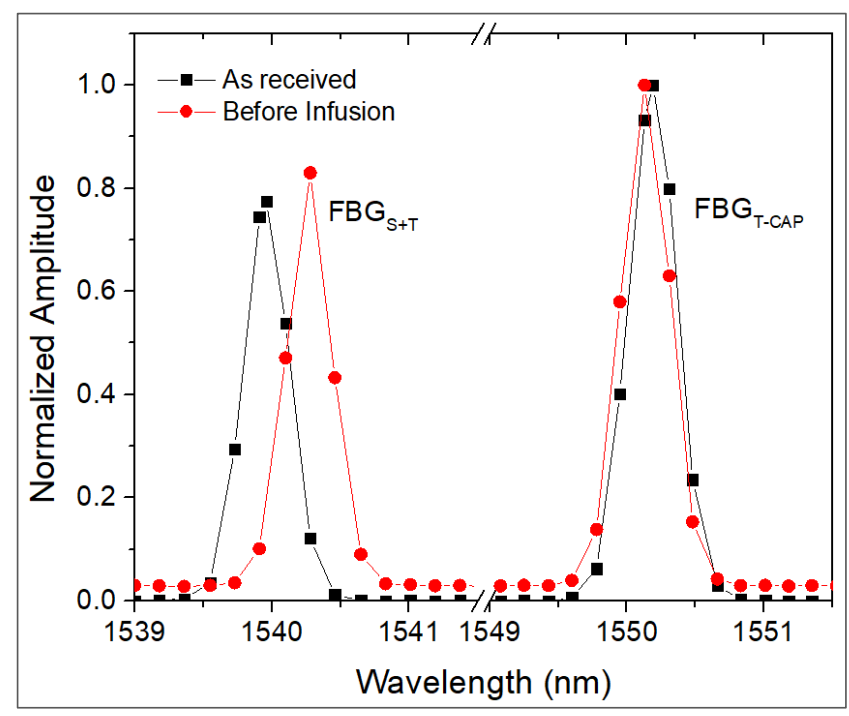

Fig. 14 Wavelength spectrum of a free SDOF, as received, and of the same optical fibre placed in between the carbon fibre plies in the VARI set up

As discussed in the previous section, for the case of the specimen with $\mathrm{OF}$ at B0 location and for most of the samples, there was a decrease on the Bragg wavelength of the FBG $_{S+T}$ sensor during ambient curing (Fig. 12 (b)) and post curing (Fig. 13). This is explained by resin shrinking as crosslinking takes place during ambient curing and post curing. A comparison of the residual strains measured by FBG sensors on SDOF and LDOF in the ambient curing and post curing stages is provided in table 1. Oppositely to the pre-strain values developed in the VARI process, the presented residual strain values produced in the ambient curing and post curing stages were obtained by continually following the variation of CWL instead of comparing the full FBG spectrum at the beginning and end of the curing stages.

Table 1: Measured residual strain values during ambient curing and post curing by the embedded small diameter and large diameter FBG sensors on CFRP laminates

\begin{tabular}{ccccc}
\hline \multirow{2}{*}{ Sample } & \multicolumn{4}{c}{ Residual Strain $(\boldsymbol{\mu} \varepsilon)$} \\
\cline { 2 - 5 } & & Pre-strain in the VARI set up & Ambient Curing & Post Curing \\
\cline { 2 - 5 } SDOF & B0 & 158 & 16 & -48 \\
\cline { 2 - 5 } & M-45 & 267 & -118 & -96 \\
\cline { 2 - 5 } & Average & $\mathbf{1 6 4} \pm \mathbf{8 2}$ & -372 & -35 \\
\hline \multirow{3}{*}{ LDOF } & T0 & 543 & $\mathbf{- 1 5 8} \pm \mathbf{1 6 1}$ & $\mathbf{- 6 0} \pm \mathbf{2 6}$ \\
\cline { 2 - 5 } & B0 & -156 & -350 & -156 \\
\cline { 2 - 5 } & M-45 & -66 & -5 & -133 \\
\cline { 2 - 5 } & Average & $\mathbf{1 0 7} \pm \mathbf{3 1 0}$ & -112 & -96 \\
\hline
\end{tabular}

The residual strains developed in the ambient curing stage were highly variable both on samples with SDOF and on samples with LDOF, with high standard deviations from the average values, $-158 \pm 161 \mu \varepsilon$ and $-156 \pm 144 \mu \varepsilon$, respectively. This range of values can be attributed to different vacuum pressures in the vacuum bag. The post curing 
procedure produced more uniform residual strain values among the samples, $-60 \pm 26 \mu \varepsilon$ and $-128 \pm 25 \mu \varepsilon$ for samples with SDOF and LDOF, respectively. The obtained results are comparable to the work reported by Kang et al. [16], Leng et al. [15] and Chehura et al. [14] on prepreg laminates. Moreover, it is possible to conclude that the LDOF did not contribute to higher residual strains in the final CFRP laminates.

The FBG sensors have proved to be able to follow the residual strain resulting from the processing conditions. For certain aerospace applications where tight dimension accuracies are needed, the use of FBG sensors can be beneficial to better adjust the curing temperature and cooling and heating rates to yield lower residual strains.

\section{Conclusions}

The present paper reports the embedment of optical fibres into CFRP laminates for ambient temperature curing and post curing monitoring and evaluation of residual strains developed during the vacuum assisted resin infusion process. Each sample had a single optical fibre in one of three positions along the thickness of the laminate embedded parallel to the direction of the carbon fibres to decrease the impairment of mechanical properties that the optical fibre may introduce. Every single optical fibre had a free encapsulated FBG sensor for temperature compensation and a strain and temperature sensitive FBG sensor.

FBG sensors proved to be able to detect a subtle increase of strain, in the range of 20 to $50 \mu \varepsilon$, as infusion started. This was, generally, followed by a strain decrease up to the time where resin has filled up the voids in the carbon fibre fabrics. Afterwards, strain is kept approximately constant for the remainder time of ambient curing. Yet, it is possible to identify a subtle strain decrease due to curing shrinkage at distinct times of ambient curing of the CFRP samples. A wide range of strain values, with an average value of about $160 \mu \varepsilon$ and standard deviation of the same other, were developed during ambient curing among the CFRP samples, which might be due to different vacuum pressures in the vacuum bag. The temperature sensitive FBG sensors revealed to be very sensitive to room temperature oscillations. Further curing was detectable during the heating and isothermal stages of the post curing procedure. The post curing procedure produced a narrower range of residual strains, $-60 \pm 26 \mu \varepsilon$ for SDOF and $-128 \pm 25 \mu \varepsilon$ for LDOF. Initial cure monitoring experiments performed on the resin system alone revealed significantly higher residual strains, -230 $\mu \varepsilon$ after ambient curing and $-2762 \mu \varepsilon$ after post curing. The lower residual strains developed during production of the CFRP through vacuum assisted resin infusion can be explained by the carbon fibres compaction imposed by vacuum which counteracts further compressive strains resultant from resin cure shrinkage.

The successful embedment and surviving the VARI process allowed to take advantage of the same FBG sensors for low velocity impact testing and infer what is the best sensor location in relation to impact distance, which will be reported in a future publication.

\section{Declarations}

\section{Funding}

The authors acknowledge the support of the European Regional Development Fund [grant number NORTE-01-0145FEDER-000015]; and of the European Space Agency through the Network/Partnering Initiative Program

\section{Conflicts of interest/Competing interests}

The authors declare that they do not have known competing financial interests. 


\section{Availability of data and material}

The authors are available to supply data files if needed

\section{Code availability}

Not applicable

\section{References}

[1] V. Giurgiutiu, "Introduction," in Structural Health Monitoring of Aerospace Composites, USA: Elsevier, 2016, pp. 1-23.

[2] R. S. Pierce, B. G. Falzon, and M. C. Thompson, "A multi-physics process model for simulating the manufacture of resin-infused composite aerostructures," Compos. Sci. Technol., vol. 149, pp. 269-279, 2017.

[3] H. S. Sas, P. Šimáček, and S. G. Advani, "A methodology to reduce variability during vacuum infusion with optimized design of distribution media," Compos. Part A Appl. Sci. Manuf., vol. 78, pp. 223-233, 2015.

[4] V. A. Komarov, E. I. Kurkin, and M. O. Spirina, "Composite Aerospace Structures Shape Distortion during All Stages of Vacuum Infusion Production,” Procedia Eng., vol. 185, pp. 139-145, 2017.

[5] V. Tita, J. De Carvalho, and D. Vandepitte, "Failure analysis of low velocity impact on thin composite laminates : Experimental and numerical approaches," Compos. Struct., vol. 83, pp. 413-428, 2008.

[6] M. Ramakrishnan, G. Rajan, Y. Semenova, and G. Farrell, "Overview of Fiber Optic Sensor Technologies for Strain/Temperature Sensing Applications in Composite Materials," Sensors, vol. 16, no. 1, p. 99, 2016.

[7] J. Y. H. Guo, G. Xiao, N. Mrad, "Fiber Optic Sensors for Structural Health Monitoring of Air Platforms," Sensors, vol. 11, pp. 3687-3705, 2011.

[8] A. R. Chambers, M. C. Mowlem, and L. Dokos, "Evaluating impact damage in CFRP using fibre optic sensors," Compos. Sci. Technol., vol. 67, no. 6, pp. 1235-1242, 2007.

[9] Y. Zhao and Y. Liao, "Discrimination methods and demodulation techniques for fiber Bragg grating sensors," Opt. Lasers Eng., vol. 41, no. 1, pp. 1-18, 2004.

[10] G. Zhou and L. M. Sim, "Damage detection and assessment in fibre-reinforced composite structures with embedded fibre optic sensors — review," Smart Mater. Struct., vol. 11, pp. 925-939, 2002.

[11] V. Giurgiutiu, "Fiber-Optic Sensors," in Structural Health Monitoring of Aerospace Composites, 2016, pp. 249-296.

[12] R. Di Sante, "Fibre Optic Sensors for Structural Health Monitoring of Aircraft Composite Structures: Recent Advances and Applications," Sensors, vol. 15, no. 8, pp. 18666-18713, 2015.

[13] Y. Qiu, Q. Wang, H. Zhao, J. Chen, and Y. Wang, "Review on composite structural health monitoring based on fiber Bragg grating sensing principle," J. Shanghai Jiaotong Univ., vol. 18, no. 2, pp. 129-139, 2013.

[14] E. Chehura, A. A. Skordos, C.-C. Ye, S. W. James, I. K. Partridge, and R. P. Tatam, "Strain development in curing epoxy resin and glass fibre/epoxy composites monitored by fibre Bragg grating sensors in birefringent optical fibre," Smart Mater. Struct., vol. 14, pp. 354-362, 2005.

[15] J. Leng and A. Asundi, "Structural health monitoring of smart composite materials by using EFPI and FBG 
sensors," vol. 103, pp. 330-340, 2003.

[16] H.-K. Kang, D.-H. Kang, H.-J. Bang, C.-S. Hong, and C.-G. Kim, "Cure monitoring of composite laminates using fiber optic sensors," Smart Mater. Struct., vol. 11, no. 2, pp. 279-287, 2002.

[17] S. Takeda, Y. Okabe, and N. Takeda, "Delamination detection in CFRP laminates with embedded smalldiameter fiber Bragg grating sensors," Compos. Part A, vol. 33, no. December 2013, pp. 971-980, 2002.

[18] K. Satori, K. Fukuchi, Y. Kurosawa, A. Hongo, and N. Takeda, "Polyimide-coated small-diameter optical fiber sensors for embedding in Composite Laminate Structures," Smart Struct. Mater. 2001 Sens. Phenom. Meas. Instrum. Smart Struct. Mater., vol. 4328, pp. 285-294, 2001.

[19] R. -m. Liu and D. -k. Liang, "Natural frequency detection of smart composite structure by small diameter fiber Bragg grating," J. Vib. Control, no. January, 2014.

[20] S. Minakuchi, Y. Okabe, and N. Takeda, "Real-time detection of debonding between honeycomb core and facesheet using a small-diameter FBG sensor embedded in adhesive layer," J. Sandw. Struct. Mater., vol. 9, no. 1, pp. 9-33, 2007.

[21] G. Ding, H. Cao, and C. Xie, "Multipoint cure monitoring of temperature and strain of carbon fibre-reinforced plastic shafts using fibre Bragg grating sensors," Nondestruct. Test. Eval., vol. 34, no. 2, pp. 117-134, 2019.

[22] ASTM International, "ASTM E2070-13 Standard Test Methods for Kinetic Parameters by Differential Scanning Calorimetry Using Isothermal Methods,” ASTM Int., vol. i, no. Reapproved, pp. 1-12, 2018.

[23] H. L. Friedman, "Kinetics of thermal degradation of char-forming plastics from thermogravimetry. Application to a phenolic plastic," J. Polym. Sci. Part C, vol. 6, no. 1, pp. 183-195, 1964.

[24] B. Fernandez d'Arlas, L. Rueda, P. M. Stefani, K. de la Caba, I. Mondragon, and A. Eceiza, "Kinetic and thermodynamic studies of the formation of a polyurethane based on 1,6-hexamethylene diisocyanate and poly(carbonate-co-ester)diol," Thermochim. Acta, vol. 459, pp. 94-103, 2007.

[25] G. Wuzella, A. R. Mahendran, C. Beuc, and H. Lammer, "Isoconversional cure kinetics of a novel thermosetting resin based on linseed oil," J. Therm. Anal. Calorim., 2020.

[26] J. M. Barton, "The application of differential scanning calorimetry (DSC) to the study of epoxy resin curing reactions," Adv. Polym. Sci., vol. 72, pp. 111-154, 1985. 